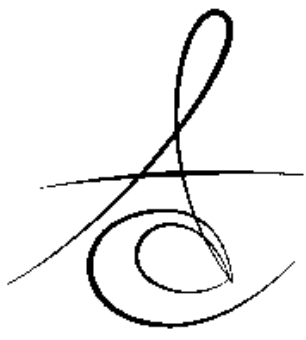

\title{
FARKLI KİMYASAL YAPILARA SAHİP DİŞ MACUNLARININ FELDSPATİK PORSELENİN YÜZEY PÜRÜZLÜLÜĞÜNE ETKİSİ ${ }^{\neq}$
}

\section{EFFECT OF DIFFERENT CHEMICAL COMPOSITION TOOTHPASTES ON SURFACE ROUGHNESS OF FELDSPATHIC PORCELAIN ${ }^{*}$}

\author{
Dr. Öğr. Üyesi Alper ÖZDOĞAN* \\ Uzm. Dt. Esra İNCESU**
}

\author{
Prof. Dr. Zeynep YEŞİL DUYMUŞ* \\ Uzm. Dt. Merve KÖSEOĞLU*
}

Makale Kodu/Article code: 2721

Makale Gönderilme tarihi; 27.03.2016

Kabul Tarihi: 29.04.2016

\section{öz}

Amaç: Bu çalışmanın amacı, farklı kimyasal yapılara sahip diş macunlarının feldspatik porselenin yüzey pürüzlülüğüne etkisinin incelenmesidir.

Gereç ve Yöntem: Çalışma kapsamında toplam 40 adet disk şeklinde porselen örnek kullanıldı. Örneklerin yüzey bitim ve cila işlemlerinden sonra profilometre cihazı ile pürüzlülükleri ölçülüp kaydedildi ve rastgele dört gruba ayrıldı. Örnek yüzeyleri dört farklı kimyasal yapıya sahip diş macunu ve elektronik diş fırçası ile günde iki kere iki dakika olmak üzere toplam bir aya denk gelecek şekilde iki saat boyunca fırçalandı. Birinci ayın sonunda profilometre ile tekrar yüzey pürüzlülükleri ölçüldü ve kaydedildi. Verilerin istatistiksel değerlendirmesi varyans analizi kullanılarak yapıldı.

Bulgular: Varyans analizinin sonuçları farklı kimyasal yapıdaki diş macunlarının feldspatik porselenin yüzey pürüzlülüğünü anlamlı derecede arttırdığını $(p<0.05)$ gösterdi. En yüksek pürüzlülük değeri (2.60 \pm 0.48 $\mu \mathrm{m})$ siyah renk koduna sahip diş macununda, en düşük pürüzlülük değerinin ise (1.96 $\pm 0.43 \mu \mathrm{m})$ kırmızı renk koduna sahip diş macununda olduğu tespit edildi.

Sonuç: Elde edilen verilere göre, diş macunlarının feldspatik porselenin yüzey pürüzlülüğünü arttırdığı, macunların kimyasal içeriğine bağlı olarak da bu artışın değişebildiği sonucuna varıldı.

Anahtar Kelimeler: Diş macunu, porselen, yüzey pürüzlülüğü.

\section{ABSTRACT}

Aim: The aim of this study was to evaluate the effect of different chemical composition toothpastes on surface roughness of feldspathic porcelain.

Material and Methods: Totally, 40 disc-shaped porcelain specimens were used in this study. After the surface polishing, the surface roughness of specimens was measured by profilometer and divided into four groups randomly. The surface of specimens was brushed two hours instead of two times a day through two minutes for a month by electric toothbrush and toothpastes, which have four different chemical compositions. After a month the surface roughness were measured by profilometer again and recorded. The statistically analysis obtained data were performed with repeated measures analysis of variance test.

Results: The results of variance test showed that statistically significant differences between different chemical composition toothpastes on surface roughness of feldspathic porcelain $(p<0.05)$. The highest surface roughness value $(2.60 \pm 0.48 \mu \mathrm{m})$ was identified in black color code toothpaste, the lowest surface roughness value $(1.96 \pm 0.43 \mu \mathrm{m})$ was identified in red color code toothpaste.

Conclusion: The obtained data presented that, the toothpastes have increased the surface roughness of feldspathic porcelain and this increasing has changed depending on the chemical composition of toothpastes.

Keywords: Toothpaste, porcelain, surface roughness.

\footnotetext{
*Atatürk Üniversitesi Diş Hekimliği Fakültesi, Protetik Diş Tedavisi Anabilim Dalı, Erzurum.

** Sakarya Ağız ve Diş Sağlığı Hastanesi, Sakarya

* 5. Uluslararası Türk ${ }^{\ddagger}$ Prostodonti ve İmplantoloji Derneği Bilimsel Sempozyumunda poster

(Poster No:201637) olarak sunulmuştur.
} 


\section{GİRIŞ}

Dental porselenler, biyouyumlu, uzun ömürlü ve estetik olma gibi üstün özelliklerinden dolayı sabit protetik restorasyonlarda yaygın olarak kullanılmaktadır. Feldspatik porselenler, stresler karşısındaki dayanıkılıkları ve estetik özellikleri nedeniyle metal seramik restorasyonlarda veneer porseleni olarak tercih edilmektedirler. ${ }^{1}$ Sabit protezler de dişler gibi ağız ortamında yer aldıkları için ağız sıvılarına, günlük tüketilen yiyecek ve içeceklerin neden olduğu plak tutulumuna maruz kalabilmektedir. Protezlerin uzun yıllar, sağlıklı bir şekilde kullanılabilmesi için temizliklerine dikkat edilmesi gerekmektedir.

Diş macunları, evde gerçekleştirilen günlük hijyenin önemli bir parçasıdır. Diş macunu kullanılarak yapılan etkin bir fırçalamayla beraber, mekanik plak uzaklaştırmasının etkinliği arttırımakta dolayısıyla çürük oluşumu ve dişeti iltihabı gibi oral hastalıkların ortaya çıkışı engellenmektedir. Diş fırçalamanın yanı sıra etkin bir temizlik için diş ipi, ara yüz fırçası ve ağız gargaraları da kullanılabilmektedir. Günlük rutin olarak yapılan diş fırçalama işlemlerinde dişler ile birlikte ağızda mevcut olan protez ve restoratif materyaller de fırçalanmaktadır. ${ }^{2,3}$

Bir diş macununun içeriği; nemlendiriciler, su, mekanik temizleyiciler, bağlayıcı ajanlar, yüzey aktif ajanlar, tatlandırıcılar, koruyucular ve tedavi edici aktif ajanlardan oluşmaktadır. ${ }^{4}$ Diş macunları ile ağız dokularına zarar vermeden maksimum temizlik sağlanabilmesine karşın, ${ }^{5}$ içeriğine bağlı olarak bir takım sorunlar oluşabilmektedir. ${ }^{6}$ Özellikle beyazlatma etkisi olan diş macunlarının içeriklerindeki aşındırıcı partiküller ya da enzimler ile ağızda bulunan diş dokusu ve restoratif materyallerin yüzeyinde değişiklik meydana getirdikleri literatürlerde belirtilmiştir. ${ }^{7-10}$ Diş macunlarının aşındırma etkisi abraziv partiküllerin yapısına bağlı olarak farklılık göstermektedir. ${ }^{11}$ Aşındırma derecesi abraziv partiküllerin yapısının yanı sıra partikül şekli ve büyüklüğüne de bağlıdır. ${ }^{12-14}$

Bu çalışma, farklı kimyasal yapılara sahip dört diş macununun feldspatik porselenin yüzey pürüzlülüğüne etkisinin incelenmesi amacıyla yapılmıştır. Çalışmanın hipotezi ise, diş macunlarının feldspatik porselenin yüzey pürüzlülüğünü arttıracağı yönündedir.

\section{GEREÇ VE YÖNTEM}

Çalışma kapsamında, 2 mm yüksekliğinde ve 10 $\mathrm{mm}$ çapında disk şeklinde toplam 40 adet feldspatik porselen (Ceramco 3, Dentsply, Burlington, New Jersey, ABD) örnek kullanıldı (Şekil 1).

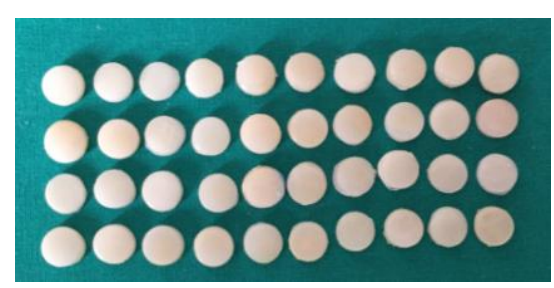

Şekil 1. Porselen örnekler

Porselen örnekleri hazırlamak için; $2 \mathrm{~mm}$ yüksekliğinde ve $10 \mathrm{~mm}$ çapında disk şeklinde mum şablonlar silikon esaslı ölçü maddesinin içerisine yerleştirildi. Ölçü maddesi sertleştikten sonra mum şablonlar çıkartıldı. İzolasyon yapıldıktan sonra dentin ve mine porseleni uyguland. Elde edilen seramik örnekler vakumlu porselen fırınında (Programat P 300 G2; Ivoclar Vivadent, Schaan, Liechtenstein) pişirildi. Yüzey düzeltme işlemlerini takiben her bir örneğin yüzeyine glaze (Ceramco 3 Stain and Glaze Liquid, Dentsply, Burlington, New Jersey, ABD) işlemi uygulandı. Cila işlemi tamamlanan örneklerin yüzey pürüzlülükleri profilometre cihazı (Surtronic 25; Taylor Hobson, Leicester, İngiltere) ile ölçülüp kaydedildi. Örnekler rastgele dört gruba ayrılarak $(n=10)$ dört farklı renk koduna sahip diş macunu; R.O.C.S. (R.O.C.S.; WDS, Rusya) (siyah), İpana 3 boyutlu beyazlık (İpana; Procter\&Gamble $\mathrm{GmbH}$, Almanya) (kırmızı), Signal beyazlatıcı sistem (Signal; Unilever Sanayi ve Ticaret A.Ş., Türkiye) (mavi), Splat medical herbst (SPLAT; Organic Pharmaceluticals LTD, Rusya (yeşil) (Şekil 2) ile elektronik diş fırçası (Oral B Vitality, Oral B, Braun, Almanya) kullanılarak günde 2 defa 2 dakika olmak üzere toplam 1 aylık fırçalama süresine karşılık gelecek şekilde 2 saat fırçalandı. Standardizasyonu sağlamak amacıyla fırçalama işlemi tek bir araştırmacı tarafından yapıldı. Kullanılan diş macunlarının üretici firmaları ve bileşimleri Tablo 1'de gösterildi. İki saatlik (bir aylık) sürenin sonunda örnekler akan su altında yıkanıp kurutuldu. Profilometre ile tekrar yüzey pürüzlülükleri ölçüldü ve kaydedildi.

Verilerin istatistiksel analizi (SPSS v20.0; SPSS Inc., Chicago, IL., ABD) varyans analizi kullanılarak

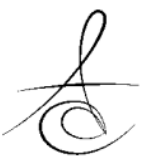


yapıldı. Coklu karsılaștırmalar icin LSD testi uygulandı.

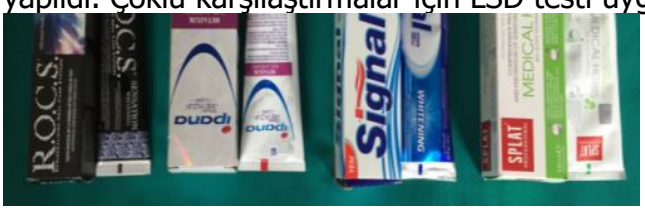

Şekil 2. Farklı renk kodlu diş macunları

\section{BULGULAR}

Grupların normal dağılım gösterip göstermediği Kolmogorov Smirnov testi ile değerlendirildi. Bütün alt grupların normal dağılım gösterdiği görüldü ( $p>0.05)$.

Tablo 1. Çalışmada kullanılan diş macunları

\begin{tabular}{|c|c|c|c|}
\hline 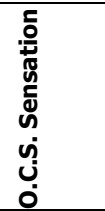 & $\begin{array}{l}\text { R.O.C.S., } \\
\text { WDS, } \\
\text { Rusya }\end{array}$ & $\begin{array}{l}\text { Sorbitol, silika, gliserin, aqua, } \\
\text { ksilitol, cocamidopropil betain, } \\
\text { flavor, xanthan gum, kalsiyum, } \\
\text { gliserofosfat, bromelain, } \\
\text { magnezyum klorid, sodyum } \\
\text { sakkarin, sodyum benzonat, o- } \\
\text { cymen-5-ol, titanyum dioksit. }\end{array}$ & Siyah \\
\hline 承 & $\begin{array}{c}\text { İpana, } \\
\text { Procter\&G } \\
\text { amble } \\
\text { GmbH, } \\
\text { Almanya }\end{array}$ & $\begin{array}{l}\text { Gliserin, hidrat silika, sodyum } \\
\text { heksametafosfat, propilen glikol, } \\
\text { aqua, PEG-6, sodyum lauril } \\
\text { sülfat, aroma, silika, poloxamer } \\
407 \text {, PEG-20M, CI 77891, } \\
\text { sodyum sakkarin, xanthan gum, } \\
\text { selüloz gum, limon, CI } 74160\end{array}$ & Kırmızı \\
\hline 兽 & $\begin{array}{c}\text { Signal, } \\
\text { Unilever } \\
\text { Sanayi ve } \\
\text { Ticaret } \\
\text { A.Ş., } \\
\text { Türkiye }\end{array}$ & $\begin{array}{l}\text { Sodyum monoflorofosfat, perlite, } \\
\text { kalsiyum karbonat, aqua, } \\
\text { sorbitol, hidrat silika, sodyum } \\
\text { laurin,sülfat, aroma, trisodyum } \\
\text { fosfat, selüloz gum, sodyum } \\
\text { sakkarin, fenilkarbinol, gliserin, } \\
\text { CI 74160, CI } 77891\end{array}$ & Mavi \\
\hline 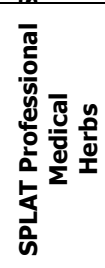 & $\begin{array}{c}\text { SPLAT, } \\
\text { Organic } \\
\text { Pharmace } \\
\text { luticals } \\
\text { LTD, } \\
\text { Rusya }\end{array}$ & $\begin{array}{l}\text { Sorbitol, hidrat silika, aqua, PEG- } \\
\text { 8, sodyum lauril sülfat, kalsiyum } \\
\text { laktat, aroma, sodyum } \\
\text { monoflorofosfat, xanthan gum, } \\
\text { sodyum metilparapen, sodyum } \\
\text { sakkarin, prolin glikol, sardunya } \\
\text { esansı, papatya, alıç, adaçayı ve } \\
\text { deniz topalağı özleri, limon, CI } \\
19140, \text { CI } 42090 .\end{array}$ & Yeşil \\
\hline
\end{tabular}

Yapılan varyans analizi sonucunda; diş macunlarının feldspatik porselenlerin yüzey pürüzlülüğünü istatistiksel olarak anlamlı $(p<0.001)$ şekilde artırdığı saptandı (Tablo 2).

Sonuçlar en yüksek yüzey pürüzlülük değerinin $(2.60 \mu \mathrm{m})$ siyah renk koduna sahip diş macunlarında, en düşük pürüzlülük değerinin ise (1.96 $\mu \mathrm{m})$ kırmızı renk koduna sahip diş macunlarında olduğunu gösterdi (Tablo 3).
Tablo 2. Varyans analizi sonuçları

\begin{tabular}{|c|c|c|c|c|c|}
\hline Gruplar & Ölçümle & Ortalama & $\begin{array}{c}\text { Standart } \\
\text { Sapma }\end{array}$ & $\begin{array}{c}\text { Serbestlik } \\
\text { Derecesi }\end{array}$ & $\mathbf{p}$ \\
\hline Siyah & $\begin{array}{l}\text { p1- } \\
\text { p2 }\end{array}$ & $\begin{array}{l}- \\
.91800\end{array}$ & .29279 & 9 & .000 \\
\hline Kırmızı & $\begin{array}{l}\text { p1- } \\
\text { p2 }\end{array}$ &. & .43690 & 9 & .035 \\
\hline Mavi & $\begin{array}{l}\text { p1- } \\
\text { p2 }\end{array}$ & .53800 & .54098 & 9 & .012 \\
\hline Yeşil & $\begin{array}{l}\text { p1- } \\
\text { p2 }\end{array}$ & .40000 & .48917 & 9 & .029 \\
\hline Toplam & $\begin{array}{l}\text { p1- } \\
\text { p2 }\end{array}$ & $\begin{array}{l}- \\
.54950\end{array}$ & .48907 & 39 & .000 \\
\hline
\end{tabular}

p2: İkinci pürüzlülük ölçümü

Tablo 3. Ortalama yüzey pürüzlülük değerleri ve LSD çoklu karşılaştırma testi sonuçları

\begin{tabular}{|l|l|l|l|}
\hline Gruplar & Ortalama $(\boldsymbol{\mu m})$ & Standart Sapma $(\boldsymbol{\mu m})$ & $\mathbf{N}$ \\
\hline Siyah & $2.60^{\mathrm{a}}$ & .47 & 10 \\
\hline Kırmızı & $1.96^{\mathrm{b}}$ & .43 & 10 \\
\hline Mavi & $2.58^{\mathrm{a}}$ & .58 & 10 \\
\hline Yeşil & $2.10^{\mathrm{b}}$ & .72 & 10 \\
\hline Toplam & 2.31 & .61 & 40 \\
\hline
\end{tabular}

\section{TARTIŞMA}

$\mathrm{Bu}$ çalışmada farklı kimyasal yapıdaki diş macunlarının feldspatik porselenin yüzey pürüzlülüğünü istatistiksel olarak artırdığından dolayı başlangıçta kurulan hipotez kabul edilmiştir.

Diş macunu tüpleri üzerindeki kare şeklindeki renk kodlarının diş macununun kimyasal içeriğini gösterdiği; siyah rengin tamamen kimyasal, kırmızı rengin doğal ve kimyasal, mavi rengin doğal ve ilaçlı, yeşil rengin ise tamamen doğal olduğu söylenmektedir. Ancak bu konuda farklı görüşler ortaya atılmış ve renk kodlarının diş macunlarının kimyasal yapıları hakkında bilgi vermediği ifade edilmiştir. Bu konuyla ilgili olarak diş macunu tüplerinin altında yer alan renkli kutucuklara "göz işareti" denildiği, bu işaretin elektronik makinelerin tüpü nereden kesmesi gerektiğini gösterdiği ve ayrıca bu renkli kutucukların paketleme işlemlerinde de kolaylık sağladığı belirtilmiştir. ${ }^{15}$ Farklı kimyasal yapıya sahip diş macunları piyasaya sunulmuştur. Bu macun türlerinin en büyük hedefi etkin bir temizlik ve beyazlatma sağlamaktır. ${ }^{16} \mathrm{Bu}$ nedenle bu tür diş macunları genellikle kombinasyon halinde veya ayrı ayrı olarak hidrojen peroksit, carbamide peroksit, sodyum bikarbonat, hidrat silika veya aluminyum oksit içermektedir. ${ }^{16,17}$ Birçok bitkisel diş macununun da

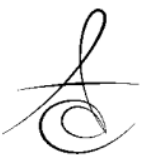


antimikrobiyal özelliklere sahip olduğu belirtilmiştir. ${ }^{18}$

Ağız, diş ve çevre dokuların sağlığının devam ettirilebilmesi, biyolojik durumun bozulmaması için düzenli bir şekilde dişlerin fırçalanması ve oral hijyenin sağlanması gerekmektedir. Oral dengenin korunması için dişlerle birlikte ağızda mevcut olan restorasyonlar da fırçalanmalıdır. Ancak diş macunlarının içeriğinde bulunan yüksek orandaki aşındırıcılara bağlı olarak, dişeti çekilmesi, servikal aşınma, dentin hassasiyeti ve restorasyonlarda zararlar meydana gelebilmektedir. ${ }^{19-21}$

Diş macunlarının mine ve restoratif materyaller üzerindeki aşındırıcı etkisi ile ilgili çok sayıda çalışma yapılmıştır. ${ }^{19,20,22,23}$ Heintze ve Forjanic ${ }^{24} 16$ kompozit rezin, 4 seramik ve 1 amalgamdan oluşan toplam 21 farklı materyalin firçalama sonrası yüzey pürüzlülüklerini değerlendirmişler, hibrit kompozitlerin mikrofil kompozitlere oranla yüzey değişimlerine daha yatkın olduklarını, seramiklerin ve amalgamın yüzey pürüzlülüğünde herhangi bir artışın olmadığını saptamışlardır. Atalı ve arkadaşları ${ }^{25}$ yaptıkları in-vitro çalışma sonucunda fırçalama sonrası mikro hibrit ve nano kompozitlerin yüzey pürüzlülüklerinde istatistiksel olarak anlamlı değişim olmadığını ifade etmişlerdir. Yeşil Duymuş ve arkadaşları ${ }^{26}$ farklı restoratif materyallerden dental porselenlerin firçalama ile oluşan abrazyona en dirençli materyal olduğunu bildirmişlerdir.

Garza ve arkadaşları ${ }^{27}$ iki farklı tam seramik örneklere uyguladıkları 12 yıllık fırçalama işleminin, Empress seramiklerin yüzey pürüzlülüğünü etkilemediğini, e.max Press seramiklerin pürüzlülüğünü ise artırdığını istatistiksel olarak saptamışlardır. Anil ve Bolay $^{3}$ 8,5 yıllık firçalama periyodunun feldspatik porselenin yüzey pürüzlülüğünde önemli artış meydana getirdiğini tespit etmişlerdir. Bu çalışmada, kullanılan bütün diş macunlarının feldspatik porselenin yüzey pürüzlülüğünü istatistiksel olarak anlamlı şekilde artırdığı saptanmıştır. Bu bulgu yukarıdaki çalışmaları destekler niteliktedir.

\section{SONUÇ}

Elde edilen veriler ışığında; diş macunlarının kimyasal içeriğine bağlı olarak feldspatik porselenin yüzey pürüzlülüğünü farklı derecede arttırdığı sonucuna varıımıştır.
Alper Özdoğan: ORCID ID: 0000-0003-0649-3056 Zeynep Yeşil Duymuş: ORCID ID: 0000-0002-9767-0080 Esra İncesu: ORCID ID: 0000-0001-8816-5456 Merve Köseoğlu: ORCID ID: 0000-0001-9110-9586

\section{KAYNAKLAR}

1. Kukiattrakoon B, Hengtrakool C, Kedjarune-Leggat $U$. The effect of acidic agents on surface ion leaching and surface characteristics of dental porcelains. J Prosthet Dent 2010;103:148-62.

2. Addy M, Hunter ML. Can tooth brushing damage your health?. Effects on oral and dental tissues. Int Dent J 2003;53: Suppl 3:177-86.

3. Anil N, Bolay S. Effect of toothbrushing on the material loss, roughness, and color of intrinsically and extrinsically stained porcelain used in metalceramic restorations: an in vitro study. Int J Prosthodont 2002;15:483-7.

4. Fischman SL. The history of oral hygiene products: How far have we come in 6000 years? Periodontol 2000;15:7-14.

5. Vincentini BC, Braga SRM, Sobral MAP. The measurement in vitro of dentine abrasion by toothpastes. Int Dent J 2007;57:314-8.

6. Moore C, Addy M. Wear of dentine in vitro by toothpaste abrasives and detergents alone and combined. J Clin Periodontol 2005 ;32:1242-6.

7. Hossain A, Okawa S, Miyakawa O. Effect of toothbrushing on titanium surface: an approach to understanding surface properties of brushed titanium. Dent Mater 2006;22:346-52.

8. Abouelatta OB, Abdel-Samad AA, Sakrana AA. Wear and surface roughness of current veneered materials after toothbrush/ dentifrice abrasion. J Mater Process Technol 2005;168:431-7.

9. Sharif N, MacDonald E, Hughes J, Newcombe RG, Addy $M$. The chemical stain removal properties of 'whitening' toothpaste products: studies in vitro. $\mathrm{Br}$ Dent J 2000;10:620-4.

10. Worschech CC, Rodrigues JA, Martins LR, Ambrosano GM. Brushing effect of abrasive dentifrices during at-home bleaching with $10 \%$ carbamide peroxide on enamel surface roughness. J Contemp Dent Pract 2006; 15:25-34. 
11. Pizzo G, La cara M, Ester Licata M, Pizz I, D'angelo $M$. The effects of an essential oil and an amine fluoride/stannous fluoride mouthrinse on supragingival plaque regrowth. J Periodontol 2008;79: 1177-83.

12. Maldupa I, Brinkmane A, Rendeniece I, Mihailova A. Evidence based toothpaste classification, according to certain characteristics of their chemical composition. Stomatologia 2012;14:1222.

13. Joiner A. Whitening toothpastes: a review of the literature. J Dent 2010;38 Suppl 2:e17-24.

14. Camargo IM, Saiki M, Vasconcellos MB, Avila DM. Abrasiveness evaluation of silica and calcium carbonate used in the production of dentifrices. J Cosmet Sci 2001; 52:163-7.

15. Walter S, CPP. Illustrated glossary of packaging terminology second edition. ISBN-13: 9781930268272. DEStech Publications, Inc, 2008.

16. Pfarrer AM, White DJ, Featherstone JD. Anticaries profile qualification of an improved whitening dentifrice. J Clin Dent 2001;2:30-3.

17. Kleber CJ, Moore $\mathrm{MH}$, Nelson BJ. Laboratory assessment of tooth whitening by sodium bicarbonate dentifrices. J Clin Dent 1998;9:72-5.

18. Shubhra V, Dakshi A, Vidya D, Hari P. Comparative evaluation of $0.2 \%$ [5]chlorhexidine versus herbal oral rinse on plaque induced gingivitis. J Indian Ass Pub Health Dent 2013;19:55-62.

19. Joiner A, Pickles MJ, Lynch S, Cox TF. The measurement of enamel wear by four toothpastes. Int Dent J 2008;58:23-8.

20. Whitehead SA, Shearer AC, Watts DC, Wilson NH. Surface texture changes of a composite brushed with "tooth whitening" dentifrices. Dent Mater 1996;12: 315-8.

21. Wulknitz P. Cleaning power and abrasivity of European toothpastes. Adv Dent Res 1997;11: 576-9.

22. Redmalm G. Dentifrice abrasivity. The use of laser light for determination of the abrasive properties of different silicas. An in vitro study. Swed Dent J 1986;10:243-50.

23. Vieira A, Ruben JL, Huysmans MC. Effect of titanium tetrafluoride, amine fluoride and fluoride varnish on enamel erosion in vitro. Caries Res 2005;39:371-9.
24. Heintze SD, Forjanic M. Surface roughness of different dental materials before and after simulated toothbrushing in vitro. Oper Dent 2005; 30:617-26.

25. Atalı PY, Öksüz M, Topbaşı FB. Fırçalamanın ve beyazlatıcı diş macunlarının kompozitlerin yüzey özelliklerine etkisi, Atatürk Üniv Diş Hek Fak Derg 2014, 24:22-32.

26. Yesil Duymus Z, Orbak R, Dilsiz A. Abrasion resistance of veneering materials to tooth brushing. Dent Mater J, 2003, 22: 460-6.

27. Garza LA, Thompson G, Cho SH, Berzins DW. Effect of toothbrushing on shade and surface roughness of extrinsically stained pressable ceramics. J Prosthet Dent 2016;115(4):489-94.

\author{
Yazışma Adresi \\ Prof. Dr. Zeynep YEŞİL DUYMUŞ \\ Atatürk Üniversitesi \\ Diş Hekimliği Fakültesi Protetik Diş Tedavisi \\ Anabilim Dalı, Erzurum \\ E- Mail: zyesilz@hotmail.com
}

